\title{
Comparison of short- and long-term effects of betaxolol and timolol on human retinal circulation
}

\begin{abstract}
Purpose To determine the short- and longterm effects of betaxolol and timolol on human retinal circulation.

Methods In a double-masked, randomised, placebo-controlled study we evaluated the effects of both a one-drop application and a twice-daily 2-week application of either topical $0.5 \%$ betaxolol hydrochloride or topical $0.5 \%$ timolol maleate on the retinal circulation in 12 healthy volunteers. Laser Doppler velocimetry was used to detect changes in the retinal venous blood flow.

Results In both betaxolol- and timolol-treated eyes, intraocular pressure decreased significantly compared with baseline values after both $90 \mathrm{~min}$ and 2 weeks. In betaxololtreated eyes, retinal blood flow did not change significantly after $90 \mathrm{~min}$, but increased significantly $(14 \pm 9 \% ; p=0.02)$ compared with baseline after 2 weeks. In timolol-treated eyes, retinal blood flow decreased significantly (18 $\pm 5 \%: p=0.04)$ compared with baseline after $90 \mathrm{~min}$, and also decreased significantly

(14 $\pm 6 \% ; p=0.04)$ compared with baseline

after 2 weeks.

Conclusions Retinal blood flow increases as a long-term effect of betaxolol and decreases as both a short- and long-term effects of timolol.

Key words Betaxolol HCl, Timolol maleate, Retinal circulation, Laser Doppler velocimetry, Normal human subjects, Short-term and longterm effect
\end{abstract}

A. Yoshida

H. Ogasawara

N. Fujio

S. Konno

S. Ishiko

N. Kitaya

H. Kagokawa

T. Nagaoka

H. Hirokawa

Department of

Ophthalmology

Asahikawa Medical

University

Asahikawa

Japan

Akitoshi Yoshida, MD Department of

Ophthalmology

Asahikawa Medical

University

4-5 Nishikagura

Asahikawa

078-8510

Japan

Tel: +81166682540

Fax: +81 166682549
The intraocular pressure (IOP)-lowering effect of topical $\beta$-adrenoceptor-blocking agents has been known for nearly 20 years. ${ }^{1,2}$ Beta-blockers have become the treatment of choice for patients with elevated IOP and the early stages of glaucoma. More recently, investigators have begun to study the effects of $\beta$-blocker therapy on visual field sensitivity in patients with glaucoma $^{3-5}$ and ocular hypertension. ${ }^{3,4}$ In two separate studies, Flammer et $a l .{ }^{3}$ compared the effects of $\beta-1$ selective (betaxolol) with non-
AKITOSHI YOSHIDA,

HIRONOBU OGASAWARA, NAOKI FUJIO,

SUGURU KONNO, SATOSHI ISHIKO,

NORIHIKO KITAYA,

HIROYUKI KAGOKAWA, TAIJI NAGAOKA, HIROYUKI HIROKAWA selective (timolol) $\beta$-blocker treatment on IOP and the visual field. They found less visual field loss in betaxolol-treated patients than in timolol-treated patients, even though better IOP control was achieved with the latter. In a third study, Flammer et al. ${ }^{3}$ found evidence that betaxolol might protect the visual field in patients with ocular hypertension. Similar findings were reported by Collignon-Brach ${ }^{4}$ in patients with ocular hypertension and glaucoma, and by Kaiser et al..$^{5}$ in patients with glaucoma. These investigators concluded that factors other than IOP alone probably determine visual field outcome.

In light of those results, other investigators compared the effects of betaxolol with those of timolol on the ocular circulation in patients with primary open-angle glaucoma ${ }^{6}$ or normaltension glaucoma. ${ }^{7,8}$ In each study, betaxolol had a positive effect on various measures of ocular circulation compared with timolol.

The aim of the present study was to compare the effects of both a one-drop topical application and a twice-daily 2 week topical application of betaxolol and timolol on the retinal blood flow (RBF) in normal human subjects.

\section{Materials and methods}

Thirteen healthy men (aged 23-46 years; mean age 32 years) were recruited for this experiment. No participants had a history of systemic or intraocular disease, and none was taking topical or systemic medication during the time of the study. All eyes had a best corrected visual acuity of 20/20 or better, an IOP of less than $20 \mathrm{mmHg}$, and a normal anterior segment and fundus. Investigational review board approval was obtained for the study protocol, and written informed consent was obtained from each subject. All experimental procedures conformed to the tenets of the Declaration of Helsinki.

The pupils of both eyes of all subjects were dilated with $1 \%$ tropicamide. One drop of topical proparacaine $\mathrm{HCl} 0.5 \%$ was instilled in each eye and IOP was measured using Goldmann applanation tonometry. The axial 
length of each eye was measured by A-mode ultrasound (OcuScan, Alcon Surgical, Irvine, CA) to compute the intraocular light-scattering geometry for the laser Doppler measurements. An instant fundus photograph was taken of each eye (Nikon Retinapan 45II, Nikon, Tokyo, Japan) for selection and documentation of the laser Doppler measurement sites.

Subjects were seated for at least $5 \mathrm{~min}$ to establish steady-state measurements of heart rate (HR) and brachial artery blood pressure (BP) prior to laser Doppler testing.

A new retinal laser Doppler instrument recently described by Feke et al. ${ }^{9}$ was used to measure the blood flow in a major temporal retinal vein in both eyes of each subject. In this fundus camera-like instrument, the retinal image is focused on the face of a CCD camera and can be viewed on a TV monitor. Eye tracking is performed by projecting a stripe from a green $543 \mathrm{~nm}$ HeNe laser through a beam-steering galvanometer system onto the retinal vein of interest. The stripe is oriented perpendicular to the axis of the vessel. The stripe reflected from the retina is incident on an array sensor that detects lateral motion of the vessel and controls the galvanometer system to stabilise the centre of the green tracking stripe on the centre of the vessel. The beam from a red $670 \mathrm{~nm}$ diode laser is the laser Doppler measuring source and is centred on the green stripe. Stabilisation of the centre of the stripe on the target vessel also results in stabilisation of the red measuring beam on the target vessel.

The red Doppler-shifted light scattered from the blood cells flowing in the retinal vein is detected simultaneously in two directions separated by a fixed angle. The signals from the two photomultiplier tube detectors undergo computer-controlled spectrum analysis, and sequential measurements of the centreline retinal blood speed (RBS) over a $2 \mathrm{~s}$ time interval are performed automatically. The diameter (D) of the retinal vein is determined automatically by computer analysis of the signal produced by the image of the vein on the array sensor. The cross-sectional area of the vein at the laser Doppler measurement site (area) is calculated assuming a circular cross-section. As previously described, ${ }^{10} \mathrm{RBF}$ in the retinal vein is calculated as

$$
\mathrm{RBF}=\mathrm{RBS} \times \text { area } / 2
$$

Measurement of RBS and D were obtained at a single site along either a major superotemporal or inferotemporal retinal vein in both eyes of each subject. The same site was measured at baseline, and at $90 \mathrm{~min}$ and 2 weeks following treatment. Five measurements of RBS and D were obtained at each site. RBF was calculated from each set of measurements, and an average value was obtained.

In a double-masked randomised design following the baseline measurement of BP, HR, IOP, D, RBS and RBF, one eye of each subject received either one drop of betaxolol hydrochloride $0.5 \%$ (Betoptic, Alcon Japan, Tokyo) or one drop of $0.5 \%$ timolol maleate ophthalmic solution (Timoptol, Santen Pharmaceutical, Osaka,
Japan). The fellow eye received one drop of placebo (physiological saline $0.9 \% \mathrm{NaCl}$ ). Ninety minutes later, the measurements were repeated. Subjects refrained from eating or drinking during the 90 min interval.

After completion of the 90 min measurements, subjects continued to be treated according to the previously described protocol with either betaxolol or timolol, i.e. one drop in one eye twice daily ( 8 o'clock in

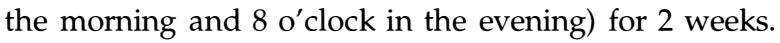
The fellow eye received one drop of placebo twice daily. At the end of 2 weeks, measurements were repeated at the same time of the day ( 2 o'clock in the afternoon) at which the 90 min measurement had been performed during the previous experiment.

\section{Statistical analysis}

Non-parametric Wilcoxon signed rank tests were used to analyse the statistical significance of changes from baseline of each measurement and to compare the percentage change of each measurement between eyes treated with either betaxolol, timolol or placebo.

Spearman rank correlation analysis was used to compare the percentage changes in perfusion pressure with the percentage changes in RBS and RBF. $p$ values of less than 0.05 were considered to be statistically significant.

\section{Results}

Of the 13 subjects recruited, 7 received betaxolol and 6 received timolol. One subject who received timolol was excluded from the study when mild bilateral corneal erosion was observed at the time of the $90 \mathrm{~min}$ measurement. No treatment was necessary, and complete recovery of both corneas occurred after 1 day. Therefore, 12 subjects completed the study, 7 of whom were treated with betaxolol and 5 with timolol.

Changes in $\mathrm{HR}$ and mean BP, calculated as $\mathrm{BP}($ diastole $)+1 / 3[\mathrm{BP}($ systole $)-\mathrm{BP}($ diastole $)]$, were analysed. Following administration of timolol, only the $90 \mathrm{~min}$ HR value was significantly lower than the baseline value $(67 \pm 5$ beats $/ \mathrm{min}$ vs $79 \pm 7 \mathrm{~min}$, respectively; $p<0.01)$. The HR value after 2 weeks of timolol treatment $(73 \pm 7$ beats $/ \mathrm{min})$ was not significantly different from the baseline value. There were no statistically significant changes in mean BP in either experiment.

\section{Summary of IOP results}

The IOP levels measured at baseline, 90 min and 2 weeks following betaxolol treatment in both betaxolol- and placebo-treated eyes are shown in Table 1. In betaxololtreated eyes, IOP decreased significantly compared with baseline values after both $90 \mathrm{~min}$ and 2 weeks $(p=0.02$ and $p=0.03$, respectively). IOP also decreased in the placebo-treated fellow eyes, but the decrease was not significant compared with baseline values after either 90 min or 2 weeks ( $p=0.11$ and $p=0.13$, respectively). At 90 
Table 1. Intraocular pressure $(\mathrm{mmHg})$ in betaxolol-treated subjects

\begin{tabular}{|c|c|c|c|c|c|c|c|c|c|c|}
\hline \multirow[b]{2}{*}{$\begin{array}{l}\text { Subject } \\
(n=7)\end{array}$} & \multicolumn{5}{|c|}{ Betaxolol eye } & \multicolumn{5}{|c|}{ Placebo eye } \\
\hline & Baseline & $\begin{array}{l}90 \mathrm{~min} \\
\text { post-Tx }\end{array}$ & $\begin{array}{c}\% \\
\text { change }\end{array}$ & $\begin{array}{l}2 \text { weeks } \\
\text { post-Tx }\end{array}$ & $\begin{array}{c}\% \\
\text { change }\end{array}$ & Baseline & $\begin{array}{l}90 \mathrm{~min} \\
\text { post-Tx }\end{array}$ & $\begin{array}{c}\% \\
\text { change }\end{array}$ & $\begin{array}{l}2 \text { weeks } \\
\text { post-Tx }\end{array}$ & $\begin{array}{c}\% \\
\text { change }\end{array}$ \\
\hline 1 & 9 & 5 & -44 & 7 & -22 & 9 & 6 & -33 & 7 & -22 \\
\hline 2 & 14 & 12 & -14 & 13 & -7 & 13 & 13 & -0 & 12 & -8 \\
\hline 5 & 17 & 12 & -29 & 15 & -12 & 18 & 17 & -6 & 17 & -6 \\
\hline 8 & 12 & 11 & -8 & 11 & -8 & 12 & 13 & 8 & 13 & 8 \\
\hline 10 & 16 & 13 & -19 & 14 & -12 & 16 & 12 & -25 & 14 & -12 \\
\hline 12 & 16 & 9 & -44 & 9 & -44 & 15 & 13 & -13 & 13 & -13 \\
\hline 13 & 13 & 11 & -15 & 13 & 0 & 12 & 12 & 0 & 13 & 8 \\
\hline \multirow[t]{4}{*}{ Mean $\pm S D$} & $14 \pm 3$ & $10 \pm 3$ & $-25 \pm 15$ & $12 \pm 3$ & $-25 \pm 15$ & $14 \pm 3$ & $12 \pm 3$ & $-10 \pm 15$ & $13 \pm 3$ & $-8 \pm 10$ \\
\hline & & & $p=0.02^{*}$ & & & & & $p=0.11^{*}$ & & \\
\hline & \multicolumn{10}{|c|}{$p=0.03^{* *}$} \\
\hline & & & & & $p=0.03^{*}$ & & & & & $p=0.13^{*}$ \\
\hline
\end{tabular}

Tx, treatment.

*Comparison with baseline (Wilcoxon signed rank test).

${ }^{* *}$ Comparison between eyes (Wilcoxon signed rank test).

$\mathrm{min}$, the IOP values in betaxolol-treated eyes were decreased significantly $(p=0.03)$ compared with the values in placebo-treated fellow eyes. However, the decrease in IOP after 2 weeks in betaxolol-treated eyes was not significantly different $(p=0.08)$ from the decrease in IOP in placebo-treated fellow eyes.

The IOP levels measured at baseline, $90 \mathrm{~min}$ and 2 weeks following timolol treatment in both timolol- and placebo-treated fellow eyes are shown in Table 2. In timolol-treated eyes, IOP decreased significantly compared with baseline values after both $90 \mathrm{~min}$ and 2 weeks ( $p=0.04$ and $p=0.04$, respectively). IOP also decreased in the placebo-treated fellow eyes, but the decrease was not significant compared with baseline values after either 90 minutes or 2 weeks $(p=0.18$ and $p=0.18$, respectively). The IOP values at both $90 \mathrm{~min}$ and
2 weeks were decreased significantly ( $p=0.04$ and $p=0.04$, respectively) in timolol-treated eyes compared with the values in placebo-treated fellow eyes.

\section{Summary of laser Doppler velocimetry results}

The RBF measurements at baseline, 90 min and 2 weeks following betaxolol treatment in both betaxolol- and placebo-treated fellow eyes are shown in Table 3. At 90 min, the values of RBF in betaxolol-treated eyes did not show any significant difference either compared with baseline values $(p=0.24)$ or compared with the values in placebo-treated fellow eyes $(p=0.18)$. However, at 2 weeks following betaxolol treatment, the values of RBF in betaxolol-treated eyes increased significantly compared both with baseline values $(p=0.02)$ and with the values in placebo-treated fellow eyes $(p=0.02)$. The RBF values

Table 2. Intraocular pressure $(\mathrm{mmHg})$ in timolol-treated subjects

\begin{tabular}{|c|c|c|c|c|c|c|c|c|c|c|}
\hline \multirow[b]{2}{*}{$\begin{array}{l}\text { Subject } \\
(n=5)\end{array}$} & \multicolumn{5}{|c|}{ Timolol eye } & \multicolumn{5}{|c|}{ Placebo eye } \\
\hline & Baseline & $\begin{array}{l}90 \mathrm{~min} \\
\text { post-Tx }\end{array}$ & $\begin{array}{c}\% \\
\text { change }\end{array}$ & $\begin{array}{l}2 \text { weeks } \\
\text { post-Tx }\end{array}$ & $\begin{array}{c}\% \\
\text { change }\end{array}$ & Baseline & $\begin{array}{l}90 \mathrm{~min} \\
\text { post-Tx }\end{array}$ & $\begin{array}{c}\% \\
\text { change }\end{array}$ & $\begin{array}{l}2 \text { weeks } \\
\text { post-Tx }\end{array}$ & $\begin{array}{c}\% \\
\text { change }\end{array}$ \\
\hline 3 & 16 & 14 & -12 & 12 & -25 & 15 & 14 & -7 & 15 & 0 \\
\hline 4 & 16 & 13 & -19 & 10 & -37 & 16 & 16 & 0 & 14 & -12 \\
\hline 6 & 11 & 9 & -18 & 10 & -9 & 12 & 12 & 0 & 12 & 0 \\
\hline 7 & 18 & 13 & -28 & 13 & -28 & 18 & 16 & -11 & 16 & -11 \\
\hline 11 & 15 & 12 & -20 & 11 & -27 & 17 & 17 & 0 & 17 & 0 \\
\hline \multirow[t]{6}{*}{ Mean $\pm S D$} & $15 \pm 3$ & $12 \pm 2$ & $-19 \pm 5$ & $11 \pm 1$ & $-25 \pm 10$ & $16 \pm 2$ & $15 \pm 2$ & $-4 \pm 5$ & $15 \pm 2$ & $-5 \pm 6$ \\
\hline & & & $p=0.04^{*}$ & & & & & $p=0.18^{*}$ & & \\
\hline & & & $L$ & & & & & \lrcorner & & \\
\hline & \multicolumn{10}{|c|}{$p=0.04^{* *}$} \\
\hline & & & & & $p=0.04^{*}$ & & & & & $p=0.18^{*}$ \\
\hline & & & & & & & $=$ & & & \\
\hline
\end{tabular}

Tx, treatment.

*Comparison with baseline (Wilcoxon signed rank test).

${ }^{* *}$ Comparison between eyes (Wilcoxon signed rank test). 
Table 3. Retinal blood flow ( $\mu \mathrm{l} / \mathrm{min})$ in betaxolol-treated subjects

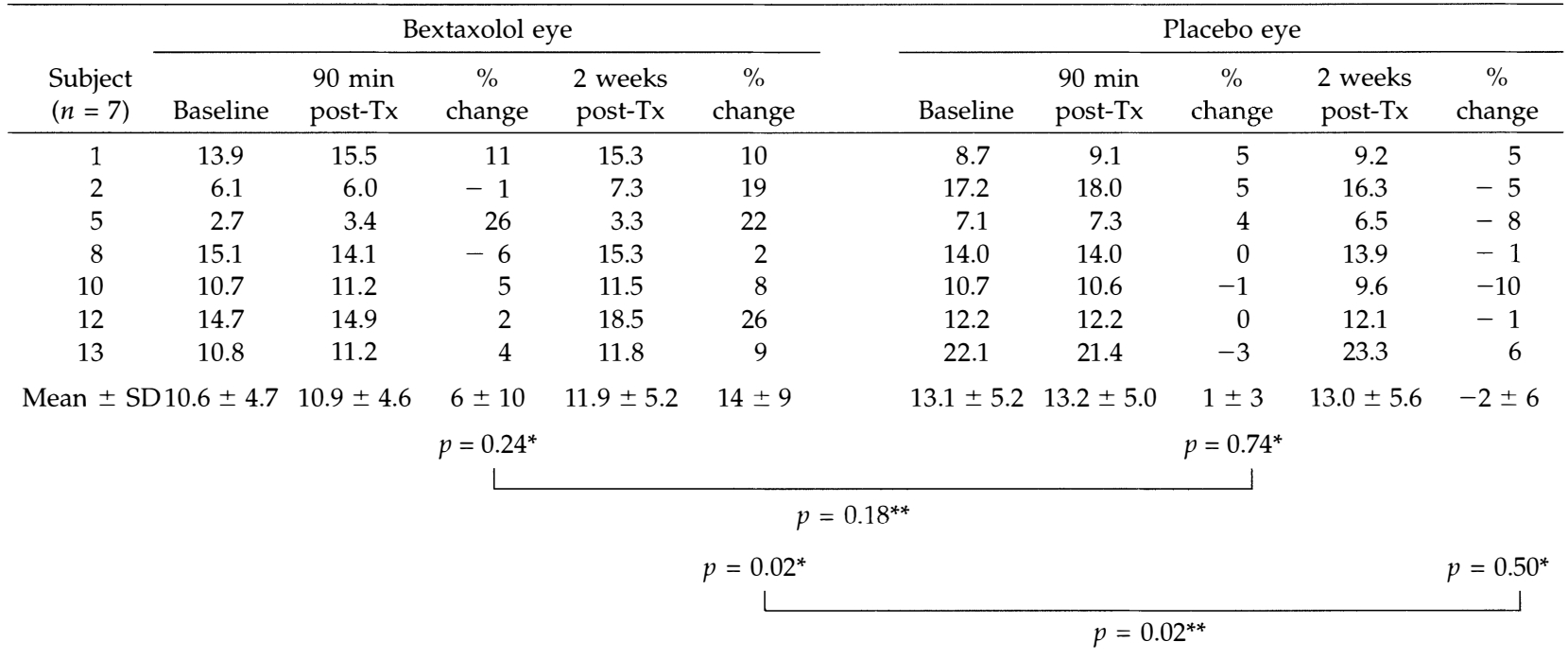

Tx, treatment.

${ }^{*}$ Comparison with baseline (Wilcoxon signed rank test).

${ }^{*}$ Comparison between eyes (Wilcoxon signed rank test).

in the placebo-treated fellow eye did not show any significant difference compared with baseline values at either 90 min or 2 weeks ( $p=0.74$ and $p=0.50$, respectively).

The RBF measurements at baseline, $90 \mathrm{~min}$ and 2 weeks following timolol treatment in both timolol- and placebo-treated fellow eyes are shown in Table 4. At 90 min, the values of RBF in timolol-treated eyes decreased significantly compared both with baseline values $(p=0.04)$ and with the values in placebo-treated fellow eyes $(p=0.04)$. At 2 weeks following timolol treatment, the values of RBF in timolol-treated eyes also decreased significantly compared both with baseline values $(p=0.04)$ and with the values in placebo-treated fellow eyes $(p=0.04)$. The RBF values in the placebo-treated fellow eyes did not show any significant difference compared with baseline values at either 90 min or 2 weeks ( $p=0.79$ and $p=0.69$, respectively).

There were no significant correlations between the changes in perfusion pressure, defined as $2 / 3$ mean $\mathrm{BP}-\mathrm{IOP}$, and the changes in RBF in either betaxololtreated or timolol-treated eyes.

\section{Discussion}

The changes in IOP following both betaxolol and timolol treatments (Tables 1,2 ) were similar to those previously reported. ${ }^{11-14}$ Gupta et al. ${ }^{11}$ found a $28 \%$ decrease in IOP in betaxolol-treated eyes and a $13 \%$ decrease in placebotreated fellow eyes of patients with ocular hypertension $120 \mathrm{~min}$ after a one-drop application of topical betaxolol. Yoshida et al. ${ }^{12}$ found a $20 \%$ decrease in IOP in timolol-

Table 4. Retinal blood flow ( $\mu \mathrm{l} / \mathrm{min})$ in timolol-treated subjects

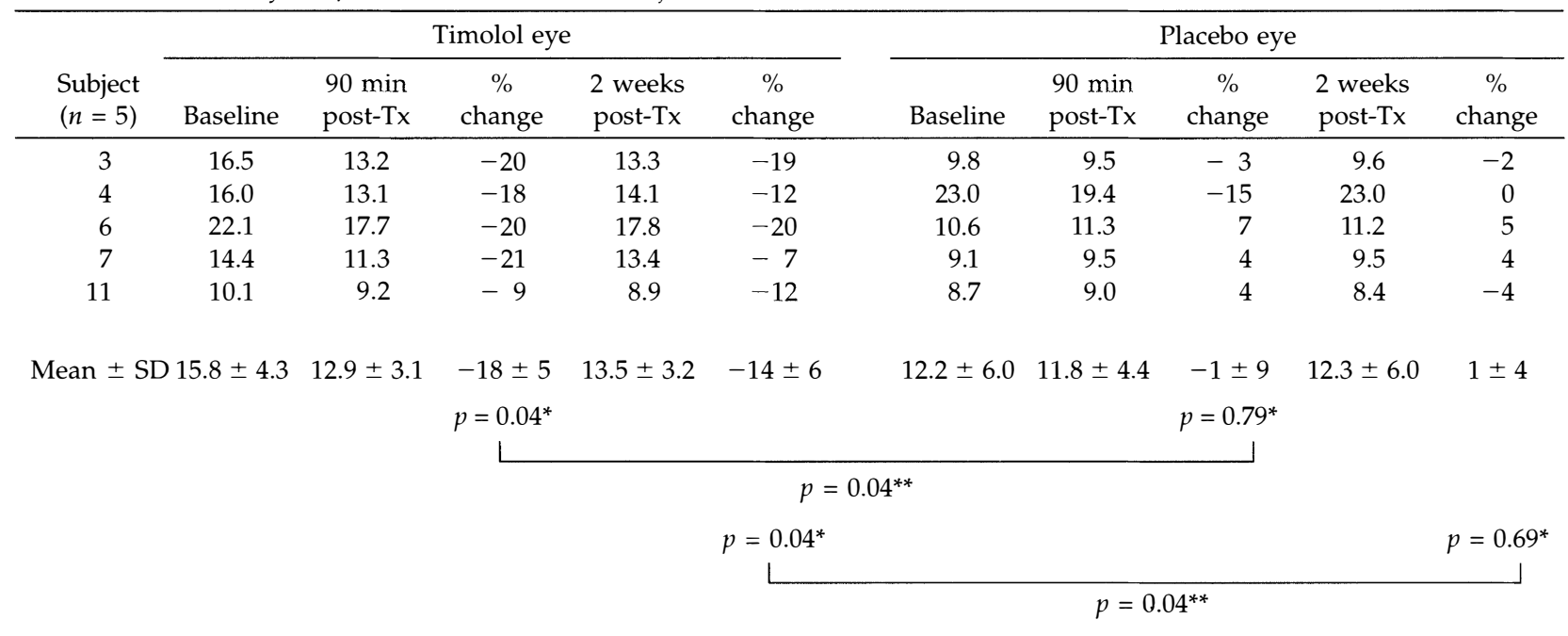

Tx, treatment.

*Comparison with baseline (Wilcoxon signed rank test).

${ }^{* *}$ Comparison between eyes (Wilcoxon signed rank test). 
treated eyes and a $6 \%$ decrease in placebo-treated fellow eyes of normal subjects 90 min after a one-drop application of topical timolol. Grunwald ${ }^{13}$ found a 35\% decrease in IOP in timolol-treated eyes and an $18 \%$ decrease in placebo-treated fellow eyes of normal subjects $90 \mathrm{~min}$ after a two-drop application of topical timolol. Grunwald ${ }^{14}$ found a $38 \%$ decrease in IOP in timolol-treated eyes and a $22 \%$ decrease in placebotreated fellow eyes of patients with ocular hypertension $120 \mathrm{~min}$ after a one-drop application of topical timolol. What is common to all of these studies is that IOP decreases not only in the drug-treated eyes but in the placebo-treated fellow eyes as well. Because of this crossover effect, differences in IOP between drug-treated eyes and placebo-treated fellow eyes may not be statistically significant. Whether the crossover effect results from the drugs acting via the central nervous system, or from a local effect of the drug reaching the fellow eye through the systemic circulation, is not known.

The changes in RBF measured following betaxolol treatment are also consistent with results previously published by Gupta et al., ${ }^{11}$ who reported that average RBF increased by $15 \%$ in patients with ocular hypertension $120 \mathrm{~min}$ after a one-drop application of topical betaxolol. The result was statistically significant $(p=0.03)$ and consistent with both the $6 \pm 10 \%$ increase measured after $90 \mathrm{~min}$ and the $14 \pm 9 \%$ increase measured after 2 weeks in the present study. To the best of our knowledge, no other studies of the effect of betaxolol on the human retinal circulation have been published.

Regarding the effects of timolol, we $\mathrm{e}^{12}$ previously reported that RBF decreased by $7 \pm 17 \%$ in normal subjects $90 \mathrm{~min}$ after a one-drop application of topical timolol. Although that decrease was not statistically significant, it is consistent with the $18 \pm 5 \%$ decrease measured after $90 \mathrm{~min}$ and the $14 \pm 9 \%$ decrease after 2 weeks in the present study. On the other hand, Grunwald $^{13,14}$ reported RBF increases in both normal subjects $(13 \pm 10 \%)$ and patients with ocular hypertension $(8 \pm 7 \%)$ after a one-drop application of topical timolol. Grunwald ${ }^{15}$ also reported an average $10 \%$ increase in RBF in normal subjects following 2 weeks of twice-daily timolol treatment. That result, however, was not statistically significant.

It is interesting to note that Martin and Rabineau ${ }^{16}$ reported that 1 week of twice-daily timolol treatment produced a statistically significant $4.1 \%$ decrease in the diameters of the larger retinal arteries in normal subjects. It has been reported ${ }^{17}$ that blood flow in such vessels varies as arterial diameter to the power 4 . Therefore, a $4.1 \%$ decrease in arterial diameter would be associated with a $17 \%$ decrease in blood flow rate, which is consistent with the results we obtained in the present study.

The study of Van Buskirk et al. ${ }^{18}$ also indicated differences between the haemodynamic effects of timolol and betaxolol. Single doses of either timolol or betaxolol produced substantial localised constriction of the arterioles that supply the ciliary processes in the rabbit eye. However, after 7 weeks of daily treatment, even though the initial vasoconstriction persisted in the timolol-treated eyes, it was no longer present in the betaxolol-treated eyes.

The mechanism of action of timolol and betaxolol on retinal haemodynamics is most likely related to the $\beta$-adrenoceptor-blocking activity of these agents. Investigators have used autoradiographic methods to show that $\mathrm{B}$-receptors are present in human retinal blood vessels ${ }^{19}$ and the human anterior optic nerve and optic nerve head. ${ }^{20}$ In these locations, most receptors identified were of the $\beta-2$ subtype. Because stimulation of the $\beta-2$ receptors in the vasculature elicits vasodilation, the antagonism of the endogenous state of vasodilation by the non-selective $\beta$-blocking agent timolol would increase the vascular resistance to flow, and thus decrease the blood flow rate in the retinal vessels. Because there are few $B-1$ receptors in human retinal vessels, the selective $B-1$ blocking agent betaxolol would have little effect on the endogenous state of vasodilation of retinal vessels and, thus, little or no effect on RBF.

The fact that betaxolol treatment actually increases RBF suggests that it has direct vascular-relaxing properties in addition to its $\beta-1$ blocking properties. Studies ${ }^{21-23}$ have demonstrated that the vascularrelaxing property of betaxolol is the result of the inhibition of calcium ion influx across vascular smooth muscle cell membranes. In other words, the action of betaxolol resembles that of a calcium channel blocker such as verapamil. It is interesting to note that Netland et al. ${ }^{24}$ recently showed that topical verapamil produced a statistically significant $10 \pm 4 \%$ increase in optic nerve head capillary blood speed in normal subjects, an increase similar in magnitude to the increase in RBF following topical betaxolol measured in the present study. The long-term beneficial effects of betaxolol treatment on visual field outcome ${ }^{3-5}$ may be related to the circulation-enhancing properties of the drug.

\section{References}

1. Corkes RL, Brubaker RF. The mechanisms of timolol in lowering intraocular pressure. Arch Ophthalmol 1978;96:2045-8.

2. Reiss GR, Brubaker RF. The mechanism of betaxolol, a new ocular hypotensive agent. Ophthalmology 1983;90:1369-72.

3. Flammer J, Collignon-Brach J, Demailly P, Graves A. Longterm visual field follow-up in betaxolol- and timolol-treated patients. In: Miles RP, editor. Perimetry update 1992/93. New York: Kugler Publications, 1993:137-42.

4. Collignon-Brach J. Longterm effect of topical beta-blockers on intraocular pressure and visual field sensitivity in ocular hypertension and chronic open-angle glaucoma. Surv Ophthalmol 1994;38:S149-55.

5. Kaiser HL, Flammer J, Stumpfig D, Hendrickson P. Longterm visual field follow-up of glaucoma patients treated with betablockers. Surv Ophthalmol 1994;38:S156-60.

6. Boles Carenini A, Sibour G, Boles Carenini B. Differences in the longterm effect of timolol and betaxolol on the pulsatile ocular blood flow Surv Ophthalmol 1994;38:S118-24. 
7. Harris A, Spaeth GL, Sergott RC, Katz LJ, Cantor LB, Martin BJ. Retrobulbar arterial hemodynamic effects of betaxolol and timolol in normal-tension glaucoma. Am J Ophthalmol 1995;120:168-75.

8. Hesse RJ. Color Doppler ultrasound measurement of betablocker response in normal tension glaucoma. Neuroophthalmology 1995;15:259-63.

9. Feke GT, Delori FC, Webb RH. Beam steering optical system and method and ophthalmic apparatus using same having spaced apart irradiation and observation paths. 1997. US patent 5, 633, 695 .

10. Feke GT, Tagawa H, Deupree DM, Gogar DG, Sebag J, Weiter $\mathrm{JJ}$. Blood flow in the normal human retina. Invest Ophthalmol Vis Sci 1989;30:58-65.

11. Gupta A, Chen HC, Rassam SMB, Kohner EM. Effect of betaxolol on the retinal circulation in eyes with ocular hypertension: a pilot study. Eye 1994;8:668-71.

12. Yoshida A, Feke GT, Ogasawara H, Goger DG, Murray DL, McMeel JW. Effect of timolol on human retinal, choroidal and optic nerve head circulation. Ophthalmic Res 1991;23:162-70.

13. Grunwald JE. Effect of topical timolol on the human retinal circulation. Invest Ophthalmol Vis Sci 1986;27:1713-9.

14. Grunwald JE. Effect of timolol maleate on the retinal circulation of human eyes with ocular hypertension. Invest Ophthalmol Vis Sci 1990;31:521-6.

15. Grunwald JE. Effect of two weeks of timolol maleate treatment on the normal retinal circulation. Invest Ophthalmol Vis Sci 1991;32:39-45.
16. Martin XD, Rabineau PA. Vasoconstrictive effect of topical timolol on human retinal arteries. Graefes Arch Clin Exp Ophthalmol 1989;227:526-30.

17. Yoshida A, Feke GT, Ogasawara H, Goger DG, McMeel JW. Retinal hemodynamics in middle-aged normal subjects. Ophthalmic Res 1996;28:343-50.

18. Van Buskirk EM, Bacon DR, Fahrenbach WH. Ciliary vasoconstriction after topical adrenergic drugs. Am J Ophthalmol 1990;109:511-7.

19. Denis P, Elena PP, Lapalus P. Autoradiographic localization of beta-adrenergic receptors in human blood retinal vessels. Chibret Int J Ophthalmol 1990;7:14-9.

20. Dawidek GMB, Robinson MI. Beta-adrenergic receptors in human anterior optic nerve: an autoradiographic study. Eye 1993;7:122-6.

21. Bessho H, Suzuki J, Tobe A. Vascular effects of betaxolol, a cardioselective $\beta$-adrenoceptor antagonist, in isolated rat arteries. Jpn J Pharmacol 1991;55:351-8.

22. Hester RK, Chen Z, Becker EJ, McLaughlin M, DeSantis L. The direct vascular relaxing action of betaxolol, carteolol and timolol in porcine long posterior ciliary artery. Surv Ophthalmol 1994;38:S125-34.

23. Hoste AM, Sys SU. The relaxant action of betaxolol on isolated bovine retinal microarteries. Curr Eye Res 1994;13:483-7.

24. Netland PA, Feke GT, Konno S, Goger DG, Fujio N. Optic nerve head circulation after topical calcium channel blocker. J Glaucoma 1996;5:200-6. 